Int. J. Dev. Biol. 51: 211-220 (2007)

doi: $10.1387 / \mathrm{ijdb} .062247 \mathrm{wm}$

Original Article

\title{
Wnt signaling in hydroid development: ectopic heads and giant buds induced by GSK-3 $\beta$ inhibitors
}

\author{
WERNER MÜLLER ${ }^{1}$, URI FRANK ${ }^{2}$, REGINA TEO $^{3}$, OFER MOKADY $^{4}$, CHRISTINA GUETTE $^{2}$ \\ and GÜNTER PLICKERT*,5
}

${ }^{1}$ Inst. Zoology, Univ. Heidelberg, Germany, ${ }^{2}$ Dept. Zoology \& Martin Ryan Mar. Sci. Inst., Nat. Univ. Ireland, Galway, Ireland,

${ }^{3}$ Cardiff School Biosc., Cardiff, U.K., ${ }^{4}$ Dept. Zoology, Tel Aviv Univ., Israel and ${ }^{5}$ Inst. Zoology, Univ. Cologne, Germany

\begin{abstract}
In Hydractinia, a colonial marine hydroid representing the basal phylum Cnidaria, Wnt signaling plays a major role in the specification of the primary body axis in embryogenesis and in the establishment of the oral pole during metamorphosis. Here we report supplementing investigations on head regeneration and bud formation in post-metamorphic development. Head and bud formation were accompanied by the expression of Wnt, frizzled and Tcf. Activation of Wnt signaling by blocking GSK-3 $\beta$ affected regeneration, the patterning of growing polyps and the asexual formation of new polyps in the colony. In the presence of lithium ions or paullones, gastric segments excised from adult polyps showed reversal of tissue polarity as they frequently regenerated heads at both ends. Phorbol myristate acetate, a known activator of protein kinase C increased this effect. Global activation of the Wnt pathway caused growing polyps to form ectopic tentacles and additional heads along their body column. Repeated treatment of colonies evoked the emergence of many and dramatically oversized bud fields along the circumference of the colony. These giant fields fell apart into smaller sub-fields, which gave rise to arrays of multiheaded polyps. We interpret the morphogenetic effects of blocking GSK-3 $\beta$ as reflecting increase in positional value in terms of positional information and activation of Wnt target genes in molecular terms.
\end{abstract}

KEY WORDS: Hydractinia (Cnidaria), GSK-3ß, axis formation, alsterpaullone, positional value

\section{Introduction}

In HydractiniaWnt signaling specifies primary axis formation in embryogenesis and governs subsequent patterning along the body axis in the developing planula larva and again during metamorphosis of the larva into a primary polyp (Plickert et al., 2006). Ectopic activation of the Wnt pathway using lithium or paullones, specific inhibitors of the serine-threonine kinase known as glycogen-synthase kinase GSK-3 $\beta$ (Wodarz and Nusse, 1998; Frame and Cohen, 2001; Jope and Johnson, 2004; Cadigan and Liu, 2006), resulted in axis multiplication by creating prospective supernumerary oral axis points in the embryo.

Hydractinia is a colonial species. The primary polyp that arises from the metamorphosing planula sprouts tube-shaped stolons at its base. These elongate, branch and form a network of channels. The stolonal network eventually transforms to a mat-like stolon plate consisting of double-layered ectoderm sandwiching the endodermal channel network (Fig. 1). New polyps emerge along these channels in more or less regular intervals and distances, which are controlled by lateral inhibition emerging from existing polyp heads (Plickert et al., 1987). The stolon plate continues to bud new polyps in its periphery at some distance from the margin, which advances by continuous planar growth on the substratum. The newly emerging polyps can only form after an oral-aboral axis has been set up de novoperpendicular to the plane of the stolonal network.

The body column of cnidarian polyps, once established during budding, preserves the capability of forming head structures and thus retains organizing potential. Regeneration of a head occurs if the apical part of the polyps has been lost. In each polyp, the capability of restoring head structures is graded down the body column. This graded property is frequently referred to and corre-

Abbreviations used in this paper: DAG, diacylglycerol; GSK, glycogen synthase kinase; PMA, phorbol-myristate acetate, also known as TPA; PKC, protein kinase C; TPA, tetradecanoyl-phorbol-myristate acetate. 

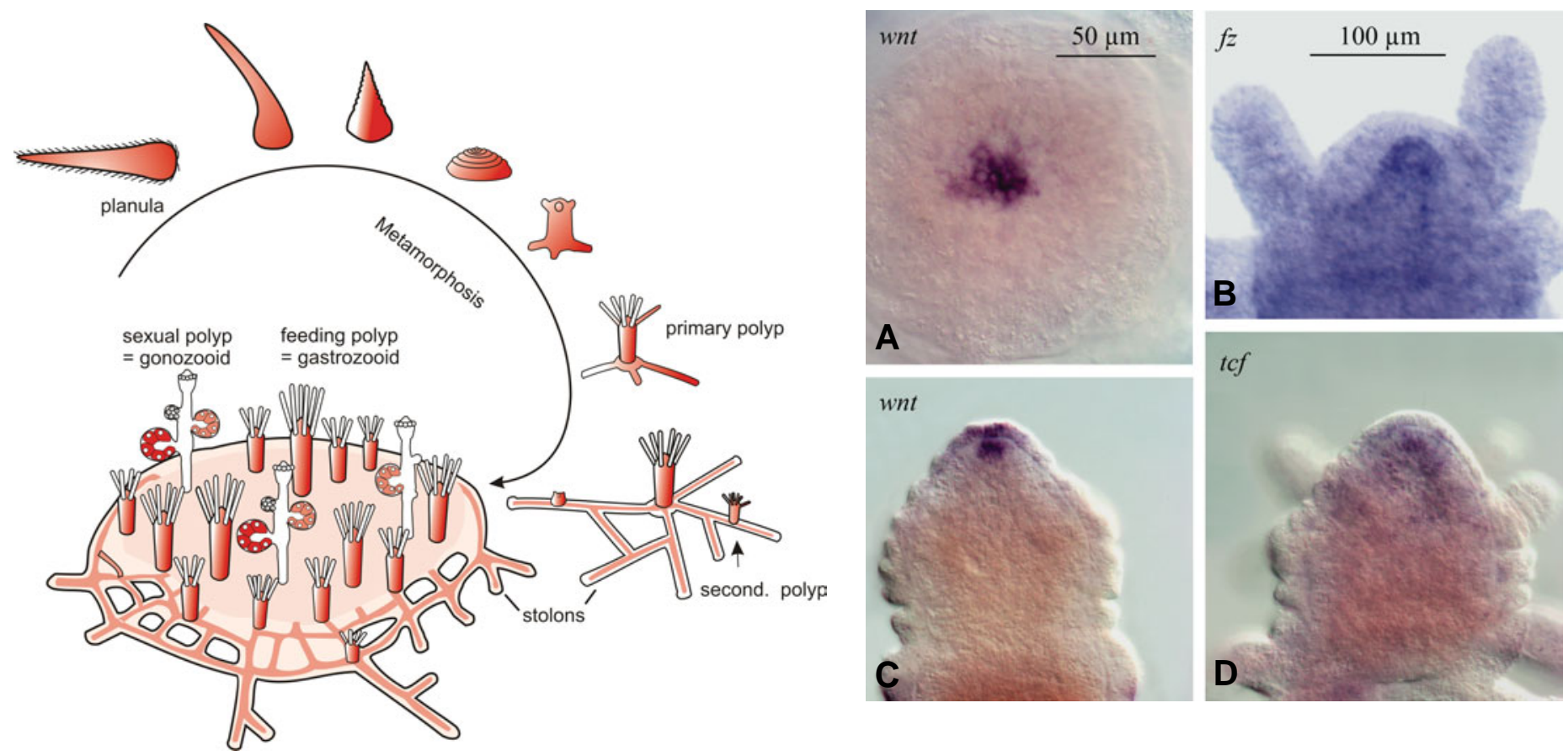

Fig. 1 (Left). Metamorphosis and postmetamorphic development of Hydractinia echinata.

Fig. 2 (Right). Patterns of expression of Wnt, frizzled and Tcfin primary polyps after completion of metamorphosis. View from above of mouth region showing expression of Wnt (A). Lateral views of polyps expressing Wnt (C), frizzled (B) and Tcf (D). In situ hybridization with autologous probes.

lated with a gradient of positional value (Müller, 1990; 1996; Wolpert, 1998; Broun and Bode, 2002; Berking, 2003; Bode, 2003; Reinhardt et al., 2004; Broun et al., 2005; Guder et al., 2006; Augustin et al., 2006). Moreover, the local positional value determines which region-specific structures will actually be realized along the body column. A certain sub-maximal value, for instance, is associated with tentacle formation.

Here we investigate the effects of GSK-3 $\beta$ inhibitors and thus the role of Wnt-signaling, in post-metamorphic development, in particular on head formation during secondary axis formation in budding and regeneration.

\section{Results}

Head formation in metamorphosis, budding and regeneration starts with expression of Wnt, frizzled and Tcf

The basic body organization of a polyp is established for the first time during metamorphosis of the planula larva into a primary polyp. Fig. 2 shows expression domains of Wnt3, Tcf and frizzled in late metamorphosis when features of a primary polyp have become evident. The $W n t$ - expressing domain is initially restricted to the ecto- and endoderm of the oral pole encircling the mouth opening. Tcftranscripts are observed in ecto- and endoderm of the mouth region but also, though less abundantly, distributed in a gradient down the body column. Transcripts of frizzledremain ubiquitously present in the endoderm of the entire body column but appear in high concentration also in a subset of, presumably differentiating, stem cells in the ectoderm (Fig. 4 B). The small Wntexpressing domain remains present throughout life of the polyp. This domain is restricted to only few cells, about 12 to 25 , in the ectoderm and some few cells resembling interstitial stem cells in the endoderm (Figs. 3, 4, 5). As observed for frizzled, transcripts of Wnt occur also in differentiating stem cells in a broad belt-like region in the middle to lower body column of adult polyps (Fig. 4).

Expression patterns during de novo secondary axis formation were studied in induced polyp budding. To avoid unpredictable influences of feeding, we used unfed, 3-day post metamorphic animals (see Fig. 1) and excised the polyp from the stolons. Normally, the stolons of primary polyps of Hydractinia form secondary polyps only after feeding when the stolons have grown out (Müller and Plickert, unpublished observations). Upon disconnecting the polyp from the stolons, the source of an inhibitory signal in spacing control (i.e. the polyp head) is removed (Plickert et al., 1987). Stolons without polyps began to bud a new polyp within 12 to $24 \mathrm{~h}$, irrespective of their length. Buds emerge as local thickenings of the stolon. They expressed Wnt and Tcf locally, while frizzled displayed a more ubiquitous intense expression (Fig. 6). Frizzledexpression continued in the endoderm although with decreasing intensity. Occasionally, a patch of more intensely stained cells was observed in the area of the future mouth. Likewise, regeneration was associated with transient expression of these genes. Samples of decapitated or bisected polyps were fixed at various time points of the regeneration process and subjected to in situ hybridization. Transcripts of Wnt, Tcf and frizzled occurred as early as 30 minutes after sectioning at both wound surfaces (Figs. 7, 8). Expression of all three genes ceased after 6 hours in the upper polyp part which completes wound healing without proceding to regenerate the lost part of the body column while Tcfand frizzledmaintained expression in the lower 
polyp fragment regenerating head structures.

\section{Gonophores, phylogenetic relicts of medusae, display a tiny Wnt-expressing spot \\ Hydractinia echinata displays polymorphism of polyps. In ma-} turing colonies a new type of polyps, the sexual polyps, arises. These polyps, also known as gonozooids or blastostyles, bud ball-shaped containers for germ cells, called gonophores. In terms of their evolutionary origin, gonophores are relicts of medusae. In Hydractiniathey remain sessile (in contrast to the situation in the sister genus Podocoryne where free swimming medusae detach from the gonozooids) and are structurally reduced to serve as gonads (Fig. 9 A). Surprisingly, a small spot of Wntexpressing cells is also seen on all the gonophores of sexual polyps. A corresponding Tcfor frizzledexpressing spot was not observed but the Hydractinia brachyury is expressed in just the same cells (Fig. 9 B).

\section{Upon treatment with paullones, isolated stolons produced more polyps}

The method to induce budding by disconnecting stolons from primary polyps (s. above) was used to verify the supposed budding-promoting effect of GSK-3 $\beta$ inhibitors. Treatment of stolons from which polyps were removed with low doses of alsterpaullone $(0.05 \mu \mathrm{M})$ for $24 \mathrm{~h}$ led to an initial delay of the anticipated budding activity but the treated stolons eventually surpassed the untreated controls in budding activity. Forty-eight $\mathrm{h}$ after their disconnection and $24 \mathrm{~h}$ after the release of the GSK$3 \beta$ blockage, $92 \%$ of the treated stolons $(n=167)$ bore at least one bud, compared to $68 \%$ of the untreated stolons $(n=106)$. The difference was highly significant (Fisher Exact $\chi^{2}$ test with Yates correction, $p<0.001$ ).

\section{Upon iterated treatment with paullones colonies formed giant buds that gave rise to ar-} rays of multi-headed polyps

In this experiment, the effect of paullones on budding activity was examined using daily fed colonies to enable repeated treatments in prolonged experiments. No polyps were removed to increase budding activity. Colonies of two different clones were repeatedly treated with low doses $(0.05$ to $0.1 \mu \mathrm{M})$ of azakenpaullone or alsterpaullone at intervals of 1-3 days for about $18 \mathrm{~h}$ per treatment. After 10 incubations treatment was stopped. A first, unusual, symptom was the emergence of many, oversized polyp buds (Fig. 10) occurring after the fifth treatment. In the following days, arrays of buds formed in a circular manner, with most of them appearing at the periphery, at short distances from the edge of the stolon plate. Most conspicuous was the enormous size of these buds, their sizes surpass-

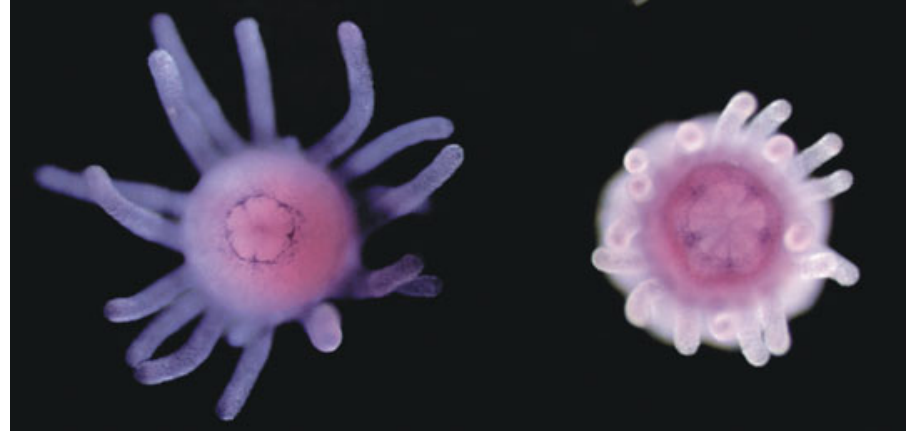

Fig. 3. Patterns of Wnt and Tcf expression in the mouth region of adult gastrozooids. Around the mouth, Wnt (left) and Tcf (right) expression continues in ecto- and endoderm, even in adult polyps. View of slightly opened mouth from above showing Wnt and Tcf expression at tissue edges. Tcf transcripts are abundant also at the bases of the five taeniolae.

ing that of normal buds by several hundred fold. Eventually, these enlarged buds split into smaller ones, which gave rise to series of polyps, many of which were bi- or multi-headed (Fig. 10).

\section{GSK-3 $\beta$ inhibition induces bipolar head regeneration; PKC activation enhances this effect synergistically}

In full-grown adult polyps the capacity to regenerate is unidirectional: excised polyps fail to regenerate the missing lower body column and stolon tissue. Isolated gastric segments replace the removed head but do not regenerate the aboral part (Müller et al., 1986). Here we examined the effect of GSK-3 $\beta$ inhibitors on head regeneration. In one experiment colonies collected from Galway Bay, Ireland, Atlantic, were used and the GSK-3 $\beta$ inhibitor chosen was lithium.

Thirty polyps were excised from sexually mature colonies and
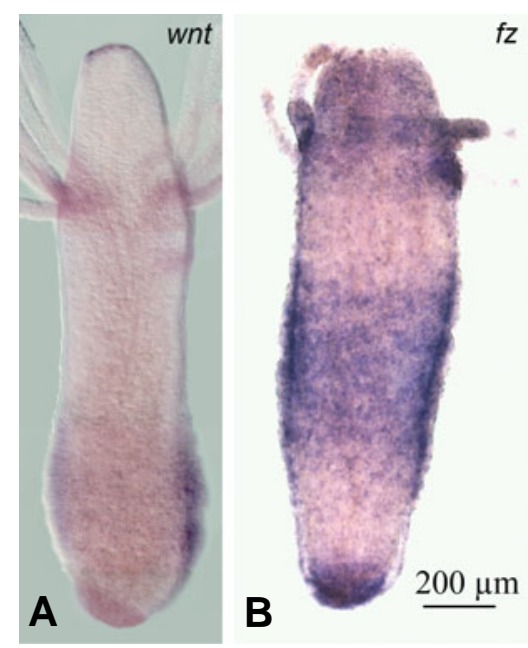

$f z$
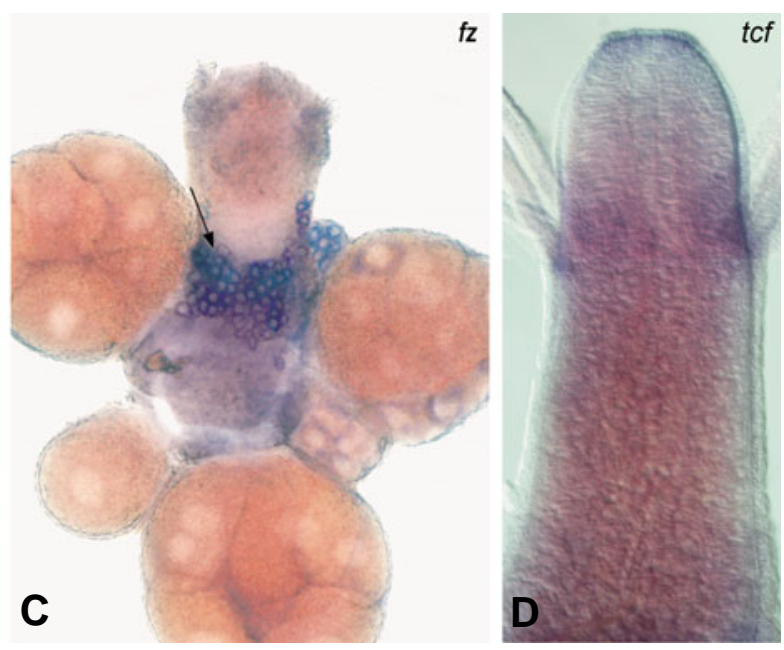

Fig. 4. Patterns of Wnt and Tcf expression along the oral-aboral axis of adult polyps. Feeding polyps (A,B,D) and female gonozooid (C)expressing Wnt3, frizzled and Tcf. Note additional expression domain of Wnt (A) and frizzled (B) in a broad ectodermal region in the middle to lower body column where differentiating stem cells are frequent. Transcripts are observed in interstitial cells and early stages of nematoblasts, see also Fig. 5D. Note that apparent lower position of stem cell girdle in (A) is due to sectioning of this specimen at a more oral axial level as compared with specimen in (B). Arrow in (C) indicates frizzled expression in oogonia. 

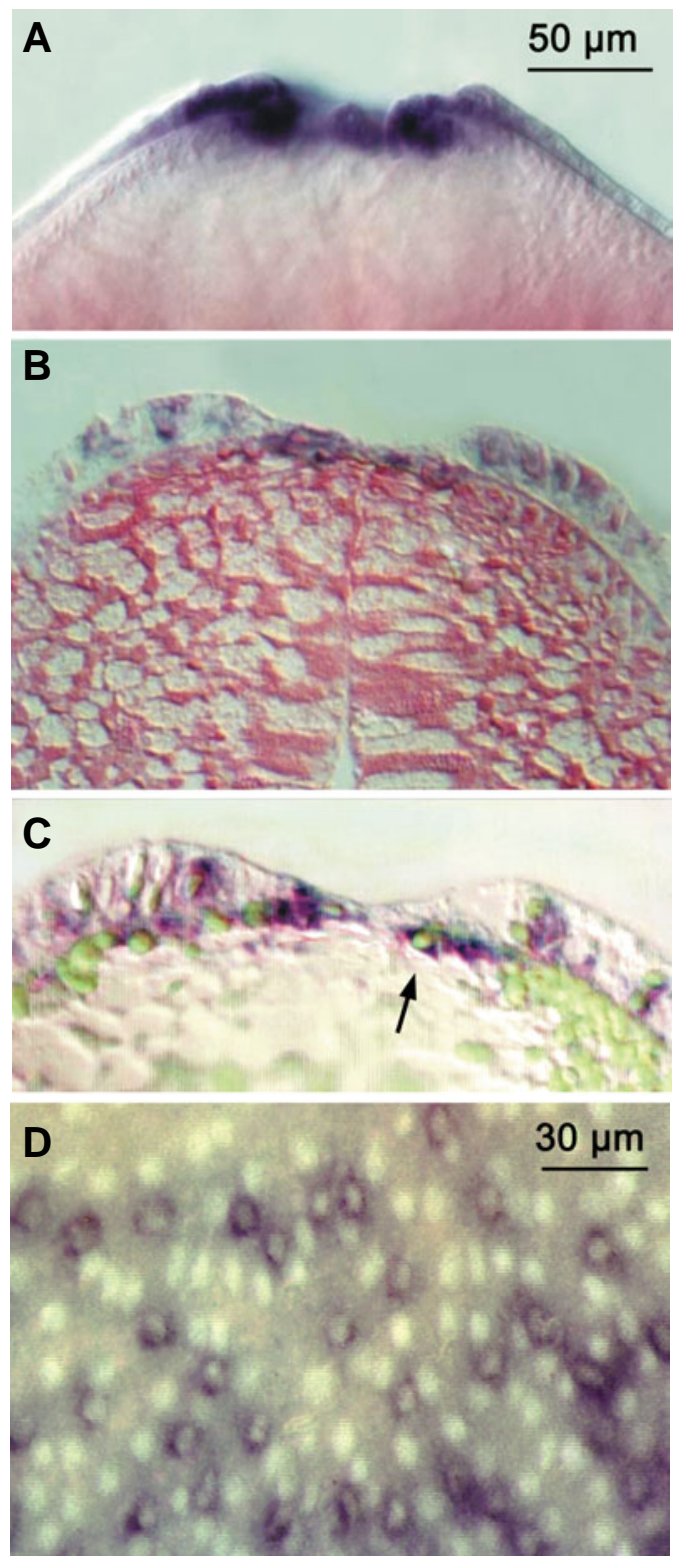

Fig. 5 (Above). Perioral Wnt3 expression and expression in differentiating stem cells. (A) Whole mount. (B) Section, tissue counterstained in red. (C) Section, nuclei DAPl-stained and false-colored in green. Note in (C) a cell in the endoderm with morphology typical for interstitial stem cells (arrow); bar in (A) corresponds also to (B) and (C). (D) Stem cells and early nematoblasts in lower body column of polyp expressing Wnt. Whole mount, nuclei DAPI-stained and false-colored in white. immediately thereafter incubated in $28 \mathrm{mM} \mathrm{LiCl}$ in seawater for 24 $\mathrm{h}$. They were then washed for several times in filtered seawater and further cultured in seawater under normal conditions. Thirty excised polyps from the same colony were left untreated as control. About $80 \%$ of the lithium treated polyps regenerated a second head at their aboral pole (Fig. $11 \mathrm{~A}$ ), while none of the control polyps did so. Instead, they healed the wound resulting from their excision and did not show any sign of neither stolon nor head growth at their aboral ends. The experiment was repeated for three times yielding similar results.

In a parallel experiment clones collected from the North Sea (near the Isles of Helgoland or Sylt, respectively) were used and the GSK-3 $\beta$ inhibitors chosen were paullones as well as $\mathrm{Li}^{+}$ions. A further aim of this study was to examine a potential synergism between GSK-3 $\beta$ inhibition and PKC activation.

The chosen wild-type clones proved to be rather insensitive to a single treatment with $\mathrm{PMA}, \mathrm{Li}^{+}$, or paullones. Therefore, a different schedule of treatment consisting of a series of pretreatments was chosen, following a schedule that had successfully been applied in Hydra magnipapillata. Upon iterated treatment with the PKC activator PMA, Hydra transformed into multiheaded forms and lost the ability to form feet (Müller, 1989; 1990; 1991).

Three colonies of a male and another three colonies of a female clone were pre-treated for 8 days before the polyps were isolated. Each colony consisted of $>200$ polyps. A pair of a male and a female colony was daily treated with $15 \mathrm{nM}$ alsterpaullone for $2 \mathrm{~h}$, a second pair with $5 \mathrm{nM}$ PMA and a third pair with $0.15 \mathrm{nM}$ alsterpaullone $+5 \mathrm{nM}$ PMA. The doses chosen were very low and the incubation time was short. Under these conditions no changes in the phenotype of the polyps and the growth pattern of the colonies were observed during this $8 \mathrm{~d}$-period of pre-treatment. But when segments were excised immediately after this period, bipolar head formation occurred (Fig. $11 \mathrm{~B}$ ). Compared to untreated controls bipolar head formation was slightly but significantly increased after pre-treatment of the colonies with the PKC activator PMA, stronger increased after treatment with alsterpaullone and strongest after exposure of colonies to a combination of PMA and paullone (Fig. 12). The difference was significant at $p<0.05$ when all corresponding values were summarized. Thus, GSK-3 $\beta$ inhibition and PKC activation have synergistic effects with respect to bipolar head formation. No such synergism was observed with respect to multiple axis formation in embryogenesis (data not shown).

Gonozooids removed from treated colonies also formed bipolar regenerates with increased frequency. They regenerated the aboral head either in the gonozooid or in the gastrozooid phenotype, respectively (Fig. $11 \mathrm{~B}$ ).

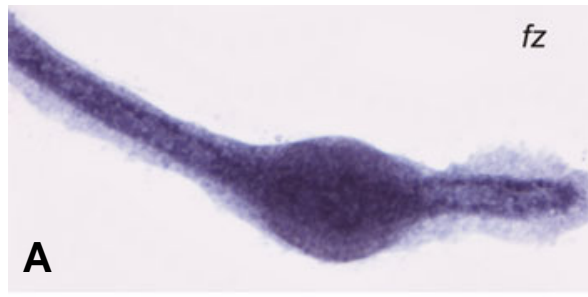

Fig. 6. Buds of polyps on stolons expressing frizzled (A), Wnt3 (B) or Tcf (C). Whole mount in situ hybridization. Budding was induced by disconnecting stolons from primary polyps as the source of an inhibitory influence.

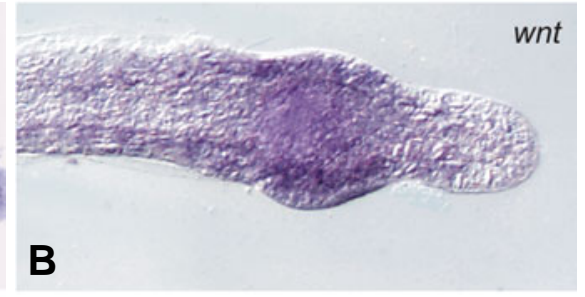

c

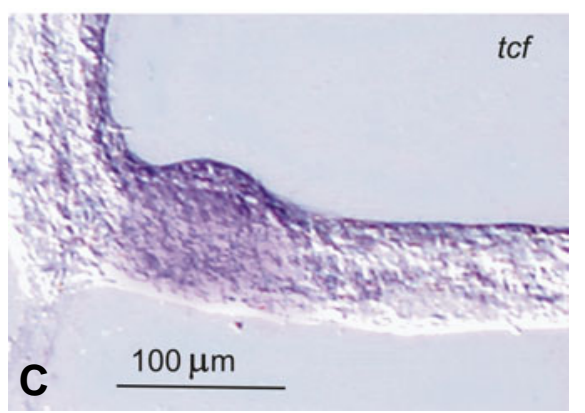


In order to probe for changes in gene expression in these experiments, polyps were excised from colonies, transferred to either DMSO or $0.25 \mu \mathrm{M}$ alsterpaullone and bisected immediately. Oral and aboral polyp halves were allowed to start regeneration for 6 hours and then analysed for Wntand Tcfexpression. Tcf expression patterns were unaltered at this time point. Wnt expression was altered, since the oral ends of lower polyp halves now expressed $W n t($ Fig. $13 \mathrm{D})$. Half of the upper pieces $(\mathrm{n}=30)$ showed expression also at their aboral ends (Fig. $13 \mathrm{C}$ ), while the
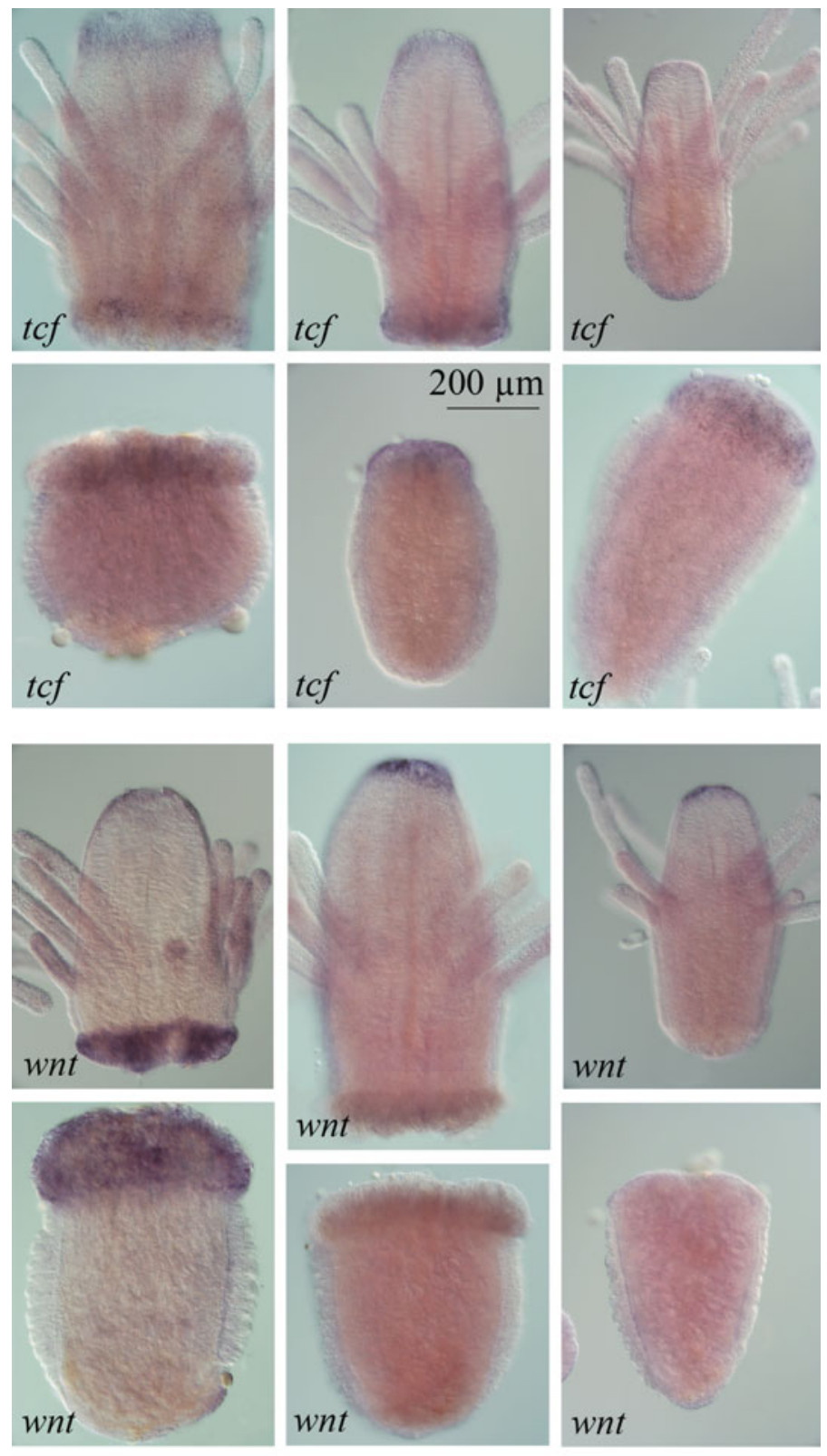

$1 \mathrm{~h}$

$3 \mathrm{~h}$ other $50 \%$ of alsterpaullone-treated upper pieces (Fig. 13 B) did not differ from DMSO-treated control pieces (Fig. $13 \mathrm{~A}$ ).

\section{Fullgrown polyps developed ectopic tentacles and hypos- tomes}

Several colonies belonging to different clones responded to periodic treatment with alsterpaullone $(0.025$ to $0.1 \mu \mathrm{M})$ with a change in the structure of extant polyps. Some of the already present polyps started to form additional heads and/or ectopic tentacles in the lower body column, indicating an increase in positional value (Fig. 14). The multi-headed polyps were phenocopies of mutant clones described in previous reports (Müller, 2002; Müller et al., 2004a). Growth of stolons ceased during this period. In two colonies the stolon plate began to regress in size with the edge retracted.

\section{Discussion}

In a previous study (Plickert et al., 2006) we have shown that activating downstream events of the Wnt pathway in metamorphosis causes a shift in opposing balanced developmental programs. Phenotypes resembled lithium-induced vegetalization in sea urchins: Planula larvae completed metamorphosis with an extended oral region whereas stolons were reduced in number and size. In terms of the concept of positional information (Müller, 1990; 1996; Wolpert, 1998; Broun and Bode, 2002; Berking, 2003; Bode, 2003; Reinhardt et al., 2004; Broun et al., 2005; Guder etal., 2006; Augustin etal., 2006) this imbalance of pattern formation along the body column reflects increase in positional value. Similarly, bipolar head regeneration as shown (Fig. 11) and the development of ectopic head structures in intact, growing polyps (Fig. 14) indicate increased positional value in the lower body column. Activation of the Wnt pathway leads to an increase in positional value and this formal interpretation readily includes budding.

These results are in line with earlier studies reporting that GSK3- $\beta$ blockage elevates positional values in Cnidaria causing supernumerary head structures in Hydractinia (Müller et al., 2004) or ectopic tentacles and increased head induction capacity

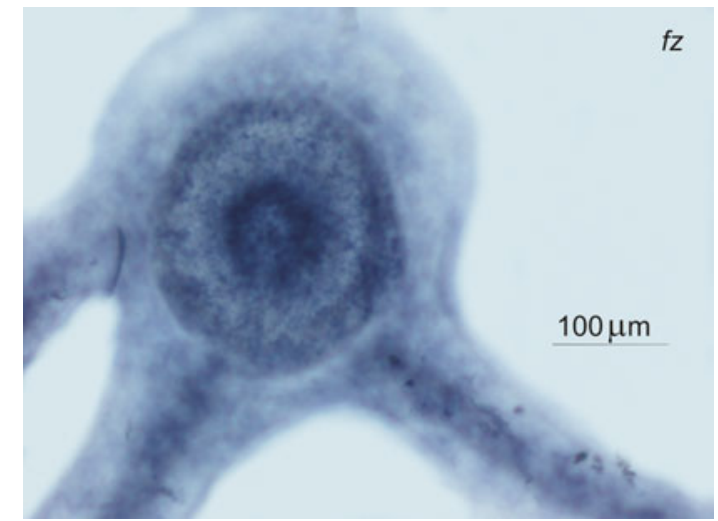

Fig. 7 (Left). Expression of Tcfor Wnt in regenerating gastrozooid polyps. Whole mount in situ hybridization of upper and lower halves of polyps 1,3 and 6 hours after sectioning.

Fig. 8 (Right). Regenerating primary polyp expressing frizzled. The head had been removed. The focus is at the top of the head-regenerating trunk. The ring like expression domain in the future mouth region disappears once the mouth has formed. The three bar-like structures are stolons sprouting from the base of the polyp. Whole mount in situ hybridization 20 hours after sectioning. 

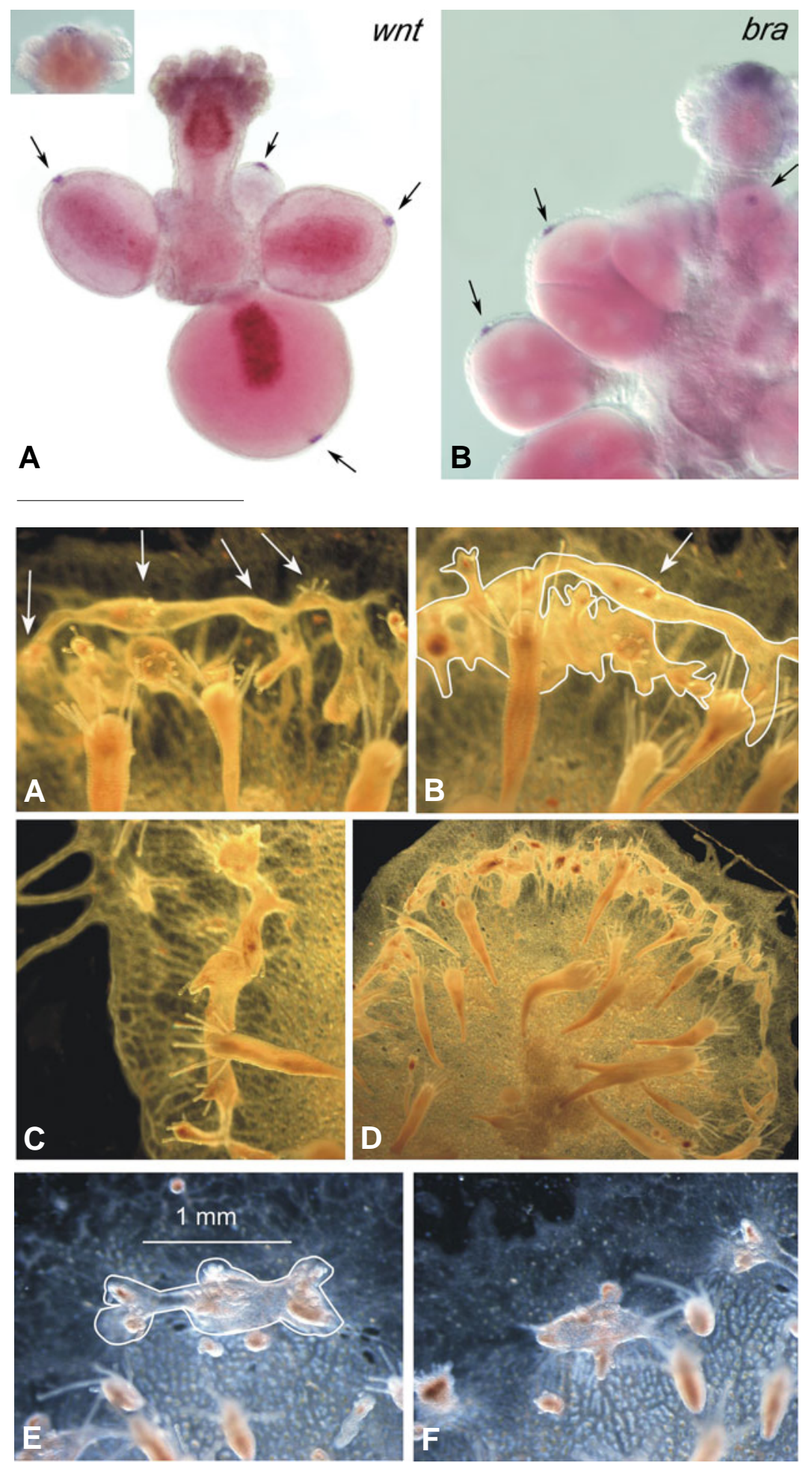

Fig. 10. Giant buds. Enlargement of bud fields observed in colonies after repeated exposure to azakenpaullone (A,B,C,D) or to alsterpaullone (E, $\mathbf{F})$. In $(A-D)$ an almost uninterrupted bud encircles the central part of the colony, producing many heads of polyps (examples indicated by arrows in $A$ and $B$ ). The almost peripheral arrangement of the buds reflects normal patterns, as in the growth-dependent extension of the colony most new polyps arise in these newly formed peripheral region. In $(C, D, E)$ multiheaded polyps are being formed by the giant buds. In $(B, E)$ the enlarged bud tissue has been outlined.
Fig. 9. Synexpression of Wnt and brachyury in sexual polyps (gonozooids) with gonophores. (A) Male specimen. Wnt expressing spots on the gonophores (arrows). Insert shows another specimen and Wnt expression domain encircling the mouth opening. Note that darkly coloured areas in the centers of gonophores do not indicate Wnt expression; they refer to natural colouring of the endodermal spadix organ. (B) Female, brachyury expression in gonophore pole cells (arrows) and in mouth region of gonozooid.

in Hydra (Broun et al., 2005). Alsterpaullone-treatment extended head associated expression domaines of HyTct, HyBra and HyWnt to lower regions of the body column (Broun et al., 2005). In Hydractinia, we observed elevated levels of Wnttranscription in alsterpaullone-treated regenerating upper polyp pieces even $6 \mathrm{~h}$ after sectioning (Fig. 13 C). This possibly reflects beginning bipolar head regeneration observed in parallel experiments and indicates a role of Wnt signaling in establishing a second organizing center. Bipolar head regeneration, though not reported in Hydra vulgaris or Hydra magnipapillata, has been shown to be inducible by the GSK-3 $\beta$ inhibitor LiCl in Pelmatohydra robusta (Yasugi, 1974). Therefore, we consider bipolar regeneration as a general effect of activated Wnt signaling by GSK-3 $\beta$ inhibitors, though the sensitivity for the treatment is clone-, strain-, or speciesspecific. A mathematical model for budding in Hydra predicted that the steepness of the gradient of positional value in the surrounding tissue decides whether the value will in- or decrease at a certain site (Berking, 2003). Accordingly, the outcome of the experiments reported here is interpreted to reflect a modulation of the steepness of this gradient.

Regenerating polyp halves strongly expressed Wht at both the oral and aboral cut surfaces but, in contrast to head-forming Hydra pieces (Hobmayer et al., 2000), only for 0.5 to 3 hours. Expression of Wntwas also observed in Hydraat the aboral pole of upper body columns forming a foot (Hobmayer, personal communication). Wht expression in Hydractinia was similar to $\beta$-catenin expression in Hydrawhich peaked about one hour after sectioning but then dereased quickly (Hobmayer et al., 2000). We observed absence of Wnt transcripts after six hours. This does not allow to conclude that Wnt protein was absent, too, at this site. In Hydractinia, both the oral and aboral wound healing tissues expressed initially Wntand Tcfbut only the oral ends of lower body column pieces regenerated heads. This indicates that control of tissue specificity at regeneration sites is not a direct function of transcriptional activity of Wnt, frizzled or Tcf. Wnt signaling depends also on genes controling intracellular transport of Wnt protein as an obligate prerequisite for secretion (Bänziger et al., 2006; Bartscherer et al., 2006). Post-translational control mechanisms including signal release control may well be a further 
critical step in specifying tissue fates after genes have been transiently active as a response to sectioning.

Budding of secondary polyps on stolons can be seen as a local increase of positional value from zero to maximum and as the establishment of a new center for axis formation. Remarkably, Wnt, frizzledand Tcfare expressed at the very beginning of bud formation. In Hydra, budding of daughter polyps starts with gene expression patterns similar to that seen in head regeneration and in putative head spots in aggregates (Hobmayer et al., 2000; Technau et al., 2000). GSK-3 $\beta$ is a downstream element in the cascade, but its blockage led to the establishment of upstream Wnt-expressing centers. This positive feedback loop corresponds aslo well to previous studies (Holstein et al., 2003; Müller et al., $2004 b)$. Here we show that blockage of GSK-3 $\beta$ increases budding activity in terms of a novel experimental phenotype: not only more buds per stolon or per colony area are produced, but the size of the bud fields is tremendously enlarged. These enlarged buds behaved like classical morphogenetic fields as they fell apart into smaller fields; each of the separated fields acquiring the potency to form a complete structure, here a polyp. Several models of biological pattern formation predict such a behavior by simulation (e.g. Meinhardt and Gierer, 2000; Meinhardt, 2002; Berking, 2003). Models also predict that regional identity along the oral aboral axis requires well-defined and graded positional values. As indicated by giant bud fields, stimulation of Wnt-signaling causes elevated positional values to extend over unusually broad areas. An equivalent effect of Wnt activation has been observed in primary polyps resulting from paullone-treated metamorphosis stages: ectopic tentacles formed all over the entire body column instead restricted to a normally narrow tentacle zone (Plickert et al., 2006). In the same study it was also shown that Wnt activation caused regenerating planula larvae to convert prospective aboral into oral tissue quality. Similar tissue conversion occurred after blockage of GSK-3 $\beta$ at aboral wound surfaces of excised polyps.

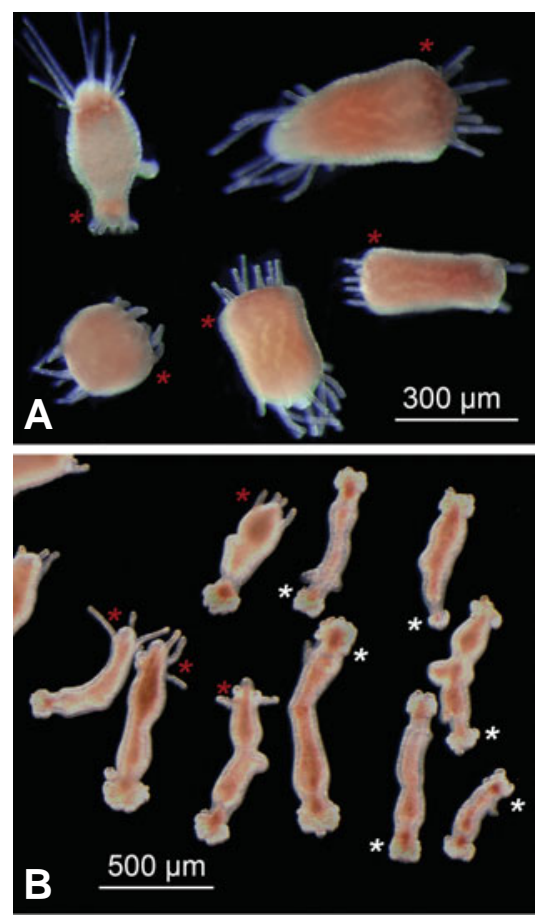

Fig. 11. Bipolar head regeneration. The polyps were removed from colonies and treated with $28 \mathrm{mM} \mathrm{LiCl}$ (A). Alternatively, colonies were exposed to low doses (15 nM) of alsterpaullone for $2 \mathrm{~h}$ per day for several times and then polyps were excised (B). Frequently, a second head was formed at the lower end of the excised polyp. (A) Bipolar feeding polyps (gastrozooids). (B) Sexual polyp regenerates. If sexual polyps (gonozooids) form a head at their lower end, it was frequently a head of a feeding polyp with long tentacles (red asterisks) instead of a gonozooid type hypostome (white asterisks).

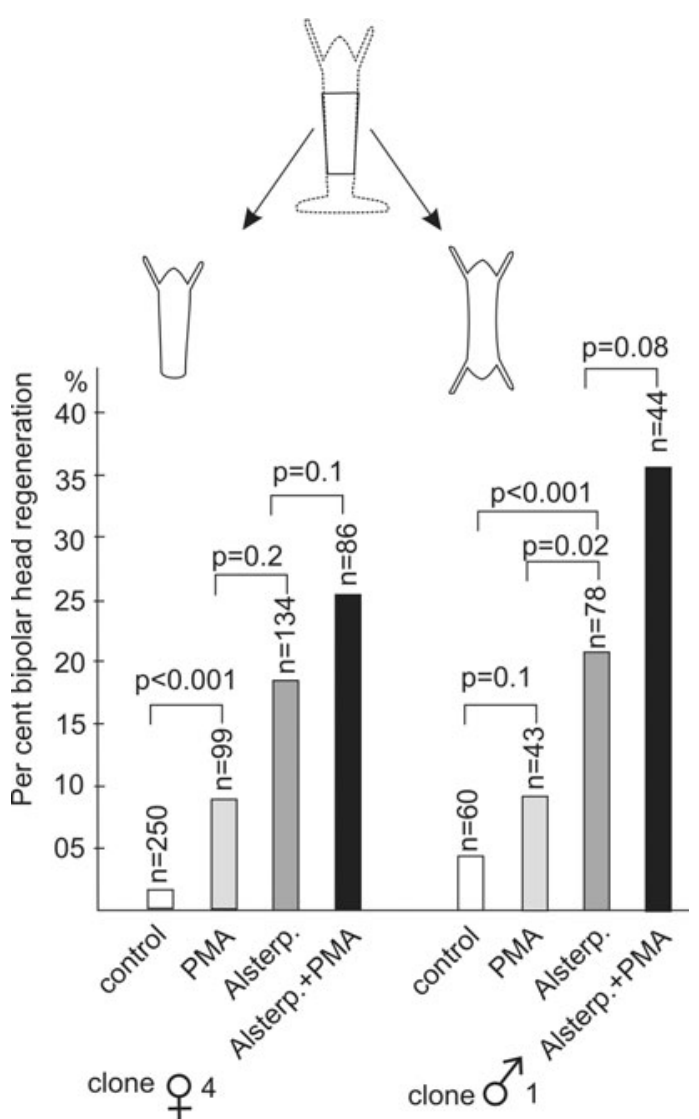

Fig. 12. Bipolar head regeneration. Quantitative data. PMA, phorbolmyristate-acetate

We conclude that one important function of the activated Wnt/ GSK-3 $\beta$ pathway in Hydractinia is to control positional values as a positive regulating signal. Blockage of GSK-3 $\beta$ is proposed to flatten positional value gradients. Decreased gradient steepness consequently causes loss of precision in defining regional identities or in delimiting a bud field to its proper size.

Since activators of PKC are also known to raise positional values (Müller, 1985; 1989; 1990; 1991) we examined a possible synergism between the Wnt pathway and PI- PKC based signaltransducing systems. Multiple axis formation during embryogenesis was evoked by GSK-3 $\beta$ inhibitors (Plickert et al., 2006), but not by PKC activators DAG or PMA (data not shown). In contrast, synergistic effects of paullones and PMA indicate that both pathways interact in adult polyps. Most recent studies associate Wnt signaling and PKC activation with the non-canonical Wnt/ calcium pathway (reviewed by Kühl et al., 2000; Strutt, 2003) but this pathway is not known to depend on Wnt3. Several other authors assume a classic Wnt/Frizzled/G-protein/PLC complex that activates $P K C$ via the release of DAG, $\mathrm{IP}_{3}$ and $\mathrm{Ca}^{2+}$. The stimulated PKC would then inhibit GSK-3 $\beta$ through phosphorylation (Cook et al., 1996; Sheldahl et al., 1999; Liu et al., 2001; Malbon et al., 2001; Kohn and Moon, 2005; Quaiser et al., 2006). Inhibition of GSK-3 $\beta$ by both PKC and paullones might be the common denominator in the synergism observed here.

With respect to Wntexpression at the oral tip of the oral-aboral axis in Cnidaria and around the blastopore in Anthozoa 

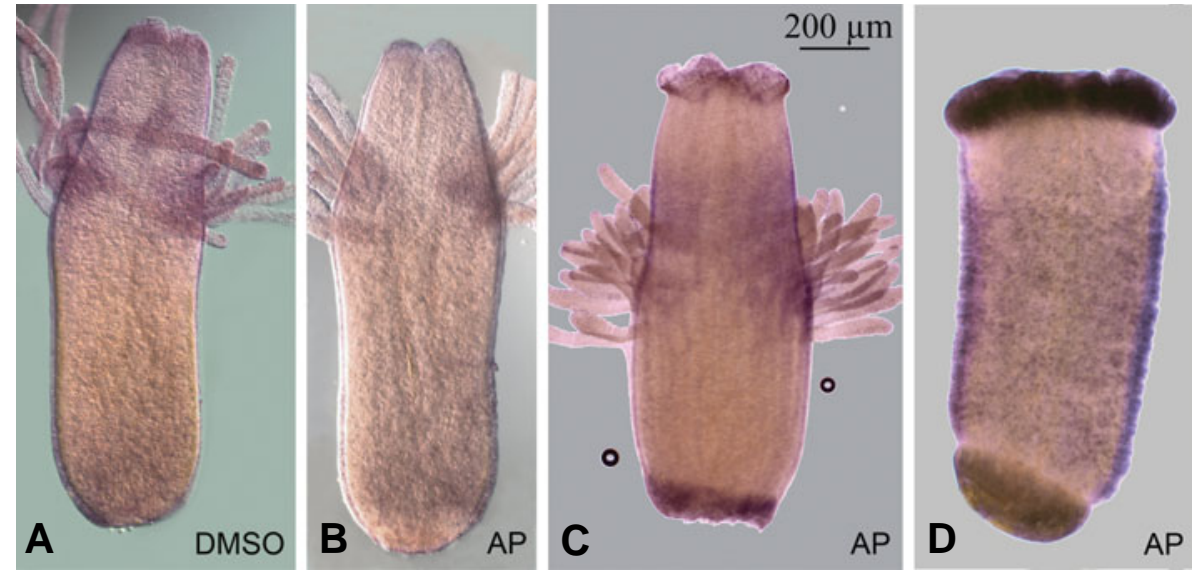

Fig. 13. Changes in Wnt expression pattern after tratment with alsterpaullone. Polyps were removed from the colony and sectioned either in $1 \mathrm{ppm} \mathrm{DMSO}$ (A) or in $0.25 \mu \mathrm{m}$ alsterpaullone (BD). Wnt in situ hybridization, $6 \mathrm{~h}$ after sectioning. (B). Example of an upper body column without enhanced expression at its aboral end, presumably representing the $50 \%$ of fragments that did not form a head at this end. (C) Example of enhanced expression at the aboral end, presumably representing the other $50 \%$ of fragments that formed a head there. (D) Enhanced expression at the oral end of a lower body column being about to regenerate a head.
(Wikramanayake, 2003; Lee et al., 2006) and other Eumetazoa (Niehrs 1999; 2004; Holland et al., 2000; Holland, 2002) we propose a supplemental role of Wnt. The mouth associated expression domain suggests involvement of Wnt-signaling in the formation or maintenance of an opening, be it the blastopore in gastrulae (Holland et al., 2000; Holland, 2002; Lee et al., 2006) or the mouth of polyps and medusae. Likewise, the spot of Wntexpression in the ectodermal layer of the gonophore may not only mark the axis of the gonophore but also a potential opening. Ectodermal cells immigrate to form the glockenkern apically at the developing gonophores. In later stages ecto- and endoderm fuse and thus form a cryptic opening (Bunting 1894). It is this site where the mature gonophore will release the gametes during spawning. A role of Wnt signaling in the formation of openings is supported by synexpression of brachyury, a gene which is usually active in tissues or cells immigrating during gastrulation or forming openings.

\section{Materials and Methods}

\section{Culture of Hydractinia}

Hydractinia was obtained from Galway Bay, The Atlantic Ocean, Ireland, or from the North Sea near the isles of Helgoland or Sylt, respectively. The animals are routinely cultured in our labs in artificial sea water (e.g., Frank et al., 2001; Müller, 2002; Plickert et al., 2003; Müller et al., 2004a).

\section{Handling of primary polyps, release of budding and regeneration}

Planula larvae were induced to enter metamorphosis by a $3 \mathrm{~h}, 100 \mathrm{mM}$ $\mathrm{CsCl}$ treatment. They were allowed to settle on cover slips. After two days metamorphosis was complete and the resulting primary polyps sprouted tube-shaped stolons at their base. Normally these stolons bud secondary polyps only when the polyps are fed and the length of the growing stolons has surpassed a minimum distance from the primary polyp. The polyp exerts an inhibitory influence (lateral inhibition) on the formation of secondary polyps. Removal of the primary polyp permits bud formation on the remaining, decoupled stolons, previous to any feeding. For induction of bud formation, the primary polyp was completely removed, for induction of regeneration the polyps were merely decapitated.

\section{Treatment with inhibitors of GSK-3}

As inhibitors of GSK-3 lithium and paullones were used. Stock solutions of paullones were prepared in DMSO and stored at $-20^{\circ} \mathrm{C}$. Working solutions were prepared immediately before use. Stock solutions were first diluted with DMSO to obtain 1000x pre-dilutions. For treatment of the animals, $1 \mu$ l of these DMSO solutions was added per ml of seawater, to obtain final working solutions containing the desired concentration of paullone and $1 \mathrm{ppm}$ DMSO. Control samples were treated with $1 \mathrm{ppm}$ DMSO. The specificity of paullones has been demonstrated previously in Hydractinia and other cnidarians (Broun et al., 2005; Teo et al., 2006 and literature therein). Lithium was effective when used in the $\mathrm{mM}$ concentrations - results are shown from treatment with $28 \mathrm{mM}$.

\section{In situ hybridization (ISH)}

ISH was performed as described previously (Plickert et al., 2003; Teo et al., 2006)

Digoxygenine-labeled sense and antisense RNA probes for in situ hybridization were generated from cDNA fragments cloned in a pGEMT-
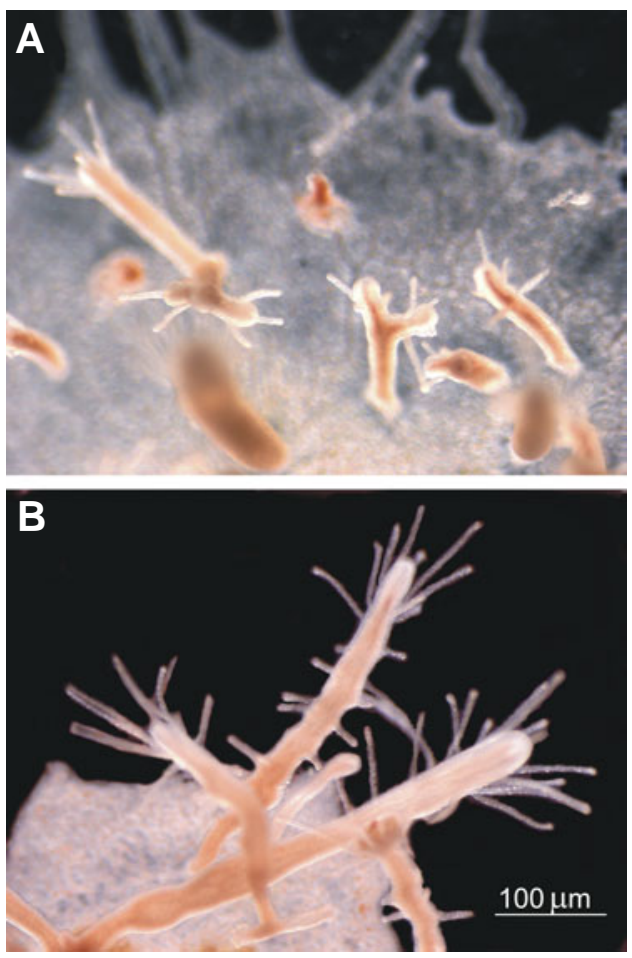

Fig. 14. Ectopic head structures in polyps of sexually mature but still growing colonies. Such forms arise predominantly in the young peripheral parts of the colony. (A) Ectopic head structures. (B) Ectopic tentacles in the lower body column. 
easy vector using T7 or SP6 RNA-polymerase as described (Plickert et al., 2006). Hybridization was performed at $57^{\circ} \mathrm{C}$.

\section{Acknowledgements}

We thank Dr. Stefan Berking for discussion. Thanks are due to Dr. Conrad Kunick, Technical University of Braunschweig, Germany, for a sample of azakenpaullone produced in his laboratory. Thanks to Dr. MichaelKroiher, University of Köln, Germany, for providing a cDNA clone of Hydractinia brachyury. This work has been supported by Deutsche Forschungsgemeinschaft, Science Foundation Ireland (SFI) and NUI Galway's Millennium Research Fund.

\section{References}

AUGUSTIN, R., FRANKE, A., KHALTURIN, K., KIKO, R., SIEBERT, S., HEMMRICH, G. and BOSCH, T.C. (2006). Dickkopf related genes are components of the positional value gradient in Hydra. Dev. Biol. 296(1): 62-70.

BÄNZIGER, C., SOLDINI, D., SCHÜTT, C., ZIPPERLEN, P., HAUSMANN, G. and BASLER, K. (2006). Wntless, a conserved membrane protein dedicated to the sectretion of Wnt proteins from signaling cells. Ce//125: 509-522.

BARTSCHERER, K., PELTE, N., INGELFINGER, D. and BOUTROS, M. (2006). Secretion of Wnt ligands requires Evi, a conserved transmembrane protein. Cell 125: 523-533.

BERKING, S. (2003). A model for budding in hydra: Pattern formation in concentric rings. J. Theoret. Biology. 222(1): 37-52.

BODE, H. (2003). Head regeneration in Hydra. Dev. Dynamics 226: 225-236.

BROUN, M. and BODE, H. (2002). Characterization of the head organizer in Hydra. Development 129: 875-884.

BROUN, M., GEE, L., REINHARDT, B. and BODE, H. (2005). Formation of the head organizer in hydra involves the canonical wnt pathway. Development 132(12): 2907-16.

BUNTING, M. (1894). The origin of sex cells in Hydractinia and Podocoryne and the development of Hydractinia. J. Morphology 9: 203-236.

CADIGAN, K.M. and LIU, Y.I. (2006). Wnt signaling: complexity at the surface. J. Cell Sci. 119 (Pt 3): 395-402.

COOK, D., FRY, M.J., HUGHES, K., SUMATHIPALA, R., WOODGETT, J.R. and DALE, T.C. (1996). Wingless inactivates glycogen synthase kinase-3 via an intracellular signalling pathway which involves a protein kinase C. EMBO J. 15(17): 4526-36.

FRAME, S. and COHEN, P. (2001). GSK-3 takes centre stage more than 20 years after its discovery. Biochem. J. 359(Pt 1): 1-16.

FRANK, U., LEITZ, T. and MÜLLER, W.A. (2001). My favorite model organism: Hydractinia echinata. Bioessays 23: 963-971.

GUDER, C., PINHO, S., NACAK, T. G., SCHMIDT, H. A., HOBMAER, B., NIEHRS, C. and HOLSTEIN, T. W. (2006). An ancient Wnt-Dickkopf antagonism in Hydra. Development 133: 901-911.

HASSEL, M. and'BIELLER, A. (1996). Stepwise transfer from high to low lithium concentrations increases the head-forming potential in Hydra vulgaris and possibly activates the PI cycle. Dev. Biol. 177(2): 439-448.

HOBMAYER, B., RENTZSCH, F., KUHN, K., HAPPEL, C.M., CRAMER VON LAUE, C., SNYDER, P., ROTHBÄCHER, U. and HOLSTEIN, T.H. (2000). Wnt signalling molecules act in axis formation in the diploblastic metazoan Hydra. Nature 407: 186-189.

HOLLAND, L. Z. (2002). Heads or tails? Amphioxus and the evolution of anteriorposterior patterning in deuterostomes. Dev. Biol. 241: 209-228.

HOLLAND, L.Z., HOLLAND, N.N. and SCHUBERT, M. (2000). Developmental expression of AmphiWnt1, an amphioxus gene in the Wnt1/wingless subfamily. Genes \& Evolution 210(10): 522-524.

HOLSTEIN, T.W., HOBMAYER, E. and TECHNAU, U. (2003). Cnidarians: an evolutionary conserved model system for regeneration. Developmental $D y$ namics 226: 257-267.

JOPE, R.S. and JOHNSON, G.V. (2004). The glamour and gloom of glycogen synthase kinase-3. Trends Biochem. Sci. 29(2): 95-102.

KOHN, A.D. and MOON, R.T. (2005). Wnt and calcium signaling: beta-catenin- independent pathways. Cell Calcium 38(3-4): 439-446.

KÜHL, M., SHELDAHL, L.C., PARK, M., MILLER, J.R. and MOON, R.T. (2000). The $\mathrm{Wnt} / \mathrm{Ca}^{2+}$ pathway. Trends Genet. 16: 279-283.

LEE, P.N., PANG, K., MATUS, D.Q. and MARTINDALE, M.Q. (2006). A WNT of things to come: evolution of Wnt signaling and polarity in cnidarians. Seminars in Cell \& Developmental Biology. 17(2): 157-167.

LIU, T., DECOSTANZO, A.J., LIU, X., WANG, H.Y., HALLAGAN, S. MOON, R.T. and MALBON, C. (2001). G protein signalling from activated rat Frizzled-1 to the beta-catenin-Lef-Tcf pathway. Science 292: 1718-1722.

MALBON, C.C., WANG, H.Y. and MOON, R.T. (2001). Wnt signalling and heterotrimeric G-proteins: strange bedfellows or a classic romance? Biochem. Biophys. Res. Comm. 287: 580-593.

MEINHARDT, H. (2002). The radial-symmetric hydra and the evolution of bilateral body plan: an old body became a young brain. Bioessays 24: 185-191.

MEINHARDT, H. and GIERER, A. (2000). Pattern formation by local self-activation and lateral inhibition. Bioessays 22: 753-760.

MÜLLER, W.A. (1985). Tumor-promoting phorbol esters induce metamorphosis and multiple head formation in Hydractinia. Differentiation 29: 216-222.

MÜLLER, W.A. (1989). Diacylglycerol-induced multihead formation in Hydra. Development 105: 306-316.

MÜLLER, W.A., (1990). Ectopic head and foot formation in Hydra: Diacylglcerolinduced increase in positional value and assistance of the head in foot formation. Differentiation 42: 131-143.

MÜLLER, W.A. (1991). Stimulation of head-specific nerve cell formation in Hydra by pulses of diacylglycerol. Dev. Biol. 147: 460-463.

MÜLLER, W.A. (1996). Pattern formation the immortal Hydra. Trends Genet. 12: 91-96.

MÜLLER, W.A. (2002). Autoaggressive, multi-headed and other mutant phenotypes in Hydractinia echinata (Cnidaria: Hydrozoa). Int. J. Dev.Biol. 46: 10231033.

MÜLLER, W.A., PLICKERT, G. and BERKING, S. (1986). Regeneration in hydrozoa: distal versus proximal transformation in Hydractinia. Roux's Archiv of Developmental Biology 195: 113-518.

MÜLLER, W.A., TEO, R. and FRANK, U. (2004a). Totipotent migratory stem cells in a hydroid. Dev. Biol. 275: 215-224.

MÜLLER, W.A., TEO, R. and MÖHRLEN, F. (2004b). Patterning a multi-headed mutant in Hydractinia: enhancement of head formation and its phenotypic normalization. Int. J. Dev. Biol. 48: 9-15.

NIEHRS, C. (1999). Head in the WNT: the molecular nature of Spemann's head organizer. Trends Genet. 15: 314-319.

NIEHRS, C. (2004). Regionally specific induction by the Spemann-Mangold organizer. Nat. Rev. Genet. 5: 425-434.

PLICKERT, G., HERINGER, A. AND HILLER, B. (1987). Analysis of spacing in a periodic pattern. Dev. Biol. 120: 399-411.

PLICKERT, G., SCHETTER, E., VERHEY-VAN-WIJK, N., SCHLOSSHERR, J., STEINBÜCHEL, M. and GAJEWSKI, M. (2003). The role of a-amidated neuropeptides in hydroid development - LWamides and metamorphosis in Hydractinia echinata. Int. J. Dev. Biol. 47: 439-450.

PLICKERT, G., JACOBY, V., FRANK, U., MÜLLER, W.A. and MOKADY, O. (2006). Wnt signaling in hydroid development: Formation of the primary axis in embryogenesis and its subsequent patterning. Dev. Biol. 298: 368-378.

QUAISER, T., ANTON, R. and KÜHL, M. (2006). Kinases and G proteins join the Wnt receptor complex. Bioessays 28: 339-343.

REINHARDT, B., BROUN, M., BLITZ, I.L. and BODE, H.R. (2004). HyBMP5-8b, a BMP5-8 orthologue, acts during axial patterning and tentacle formation in hydra. Dev. Biol. 267: 43-59.

SHELDAHL, L.C., PARK, M., MALBON, C.C. and MOON, R.T. (1999). Protein kinase $C$ is differentially stimulated by Wnt and Frizzled homologs in a G-protein dependent manner. Curr. Biol. 9: 695-698.

STRUTT, D. (2003). Frizzled signalling and cell polarisation in Drosophila and vertebrates. Development 130(19): 4501-4513.

TECHNAU U., CRAMER VON LAUE C., RENTZSCH F., LUFT S., HOBMAYER B., BODE H.R. and HOLSTEIN T.W. (2000). Parameters of self-organization in Hydra aggregates. Proc. Natl. Acad. Sci. USA. 97(22): 12127-12131. 
TEO, R., MÖHRLEN, F., PLICKERT, G., MÜLLER, W.A. and FRANKU. (2006). An evolutionary conserved role of Wnt-signaling in stem cell fate decision. Dev. Biol. 289(1): 91-99.

WIKRAMANAYAKE, A.H., HONG, M., LEE, P.N., PANG, K., BYRUM, C.A., BINCE, J.M., XU, R. and MARTINDALE, M.Q. (2003). An ancient role for nuclear $\beta$ catenin in the evolution of axial polarity and germ layer segregation. Nature 426 : 446-450.

WODARZ, A. and NUSSE, R. (1998). Mechanisms of Wht signalling in development. Annu. Rev. Cell \& Dev. Biol. 14: 59-88.

WOLPERT, L. (1998). Principles of development. Current Biology LTD and Oxford
University press, p 19 and pp 403-405.

YASUGI, S. (1974). Observations on supernumerary head formation induced by lithium chloride treatment in the regenerating hydra, Pelmatohydra robusta. Dev. Growth Diff. 16: 171-180.

Received: 17 th November 2006 Reviewed by Referees: 3rd January 2007 Modified by Authors and Accepted for Publication: 13th April 2007 Published Online: 23 rd April 2007

\section{Related, previously published Int. J. Dev. Biol. articles}

See our Special Issue on The Spemann Mangold Organizer http://www.ijdb.ehu.es/web/contents.php?vol=45\&issue=1

The zic1 gene is an activator of Wnt signaling

Christa S. Merzdorf and Hazel L. Sive

Int. J. Dev. Biol. (2006) 50: 611-617

The Wnt connection to tumorigenesis

Jürgen Behrens and Barbara Lustig

Int. J. Dev. Biol. (2004) 48: 477-487

Molecular markers for germ cell differentiation in the demosponge Suberites domuncula Sanja Perovic-Ottstadt, Helena Cetkovic, Vera Gamulin, Heinz C. Schroder, Klaus Kropt, Claire Moss, Michael Korzhev, Barbel Diehl-Seifert, Isabel M. Muller and Werner E.G. Muller

Int. J. Dev. Biol. (2004) 48: 293-305

Patterning a multi-headed mutant in Hydractinia: enhancement of head formation and its phenotypic normalization.

Werner A Müller, Regina Teo and Frank Möhrlen

Int. J. Dev. Biol. (2004) 48: 9-15

The role of alpha-amidated neuropeptides in hydroid development-LWamides and metamorphosis in Hydractinia echinata.

Günter Plickert, Eva Schetter, Nicole Verhey-Van-Wijk, Jörg Schlossherr, Marlis Steinbüchel and Martin Gajewski

Int. J. Dev. Biol. (2003) 47: 439-450 